\title{
RESPONSABILIDADE CIVIL DA AGÊNCIA PUBLICITÁRIA
}

Felipe dos Reis Barroso

Mestre em Administração (DePaul University, Chicago, EUA). Professor do curso de Direito da FA7. Advogado.

Carolina Sobreira de Oliveira

Aluna do curso de Direito da FA7. Estagiária do Tribunal de Justiça do Estado do Ceará.

carol.sobreiraa@gmail.com

Sumário: Introdução. 1. Acerca da agência publicitária. 2. Aspectos do contrato de prestação de serviços publicitários.

3. Da responsabilidade e solidariedade da agência publicitária.

4. Posicionamento dos tribunais. Considerações finais. Referências.

Resumo: O presente artigo examina a responsabilidade civil da agência publicitária, em relação aos danos causados por anúncio por ela produzido, mas previamente contratado e aprovado pelo cliente/anunciante para veiculação. Apresenta-se o conceito de agência e dos outros sujeitos que participam da relação mercadológica. Após, analisam-se aspectos contratuais desta relação, que convergem para prestação de serviços publicitários, diferenciando-o do contrato de agência. Por fim, examina-se a questão específica da responsabilidade civil da agência publicitária, bem como a do anunciante e a do veículo de comunicação, os referidos sujeitos que concorrem para que a publicidade chegue ao público, sob a óptica dos tribunais.

Palavras-chave: Agência Publicitária. Responsabilidade Civil. Solidariedade. Propaganda. Contrato de prestação de serviços publicitários.

\section{INTRODUÇÃO}

Com a intensificação da atividade comunicacional e a sofisticação da economia capitalista, que necessita mais e mais do consumo de massa para se retroalimentar, a atividade publicitária vem ganhando crescente relevância no presente século.

Tal atividade comunicacional baseia-se numa relação tripartite, que envolve anunciante (contratante do serviço da agência publicitária), agência publicitária (que presta o serviço publicitário, elaborando principalmente peças publicitárias, conforme briefing do anunciante) e veículo de comunicação (que torna pública a peça publicitária aos possíveis consumidores, serviço feito mediante paga do anunciante).

Considerando a necessidade de proteção do consumidor, parte hipossuficiente na relação consumerista, coloca-se então a questão de até onde a agência publicitária, que intermedeia a cadeia comunicacional (até pela sua denominação e natureza), pode ser responsabilizada por propaganda enganosa e/ou abusiva, de sua lavra, nos termos da legislação vigente. É o que se pretende aqui examinar, sob a óptica da doutrina e do Poder Judiciário. 


\section{ACERCA dA AGÊNCIA PUBLICITÁRIA}

Agência vem do latim agentia, que "é o estabelecimento cujo fim é prestar serviços, geralmente como intermediário em negócios alheios, mediante retribuições: agência de comissões e consignações, agência de colocações, agência de publicidade, agência de turismo, agência funerária." (BARSA, 1994, p. 71).

Do conceito supra, é possível extrair uma variedade de exemplos distintos dessa prestadora de serviços que atua intermediando relações negociais; mas, o presente artigo se restringirá, por óbvio, à agência publicitária.

O Código de Ética dos Profissionais da Propaganda (2012, online), de outubro de 1957, é o primeiro conjunto de normas que, no Brasil, busca disciplinar o assunto, assim conceituando:

3. AAgência de Propaganda é a firma organizada para exercer as funções definidas pela ABAP. e que realiza a propaganda para o cliente e promove negócios para os veículos de propaganda, que a reconhecem como tal e a ela pagam comissão.

O Conselho Executivo das Normas-Padrão (CENP), responsável por regulamentar a organização interna da agência publicitária, define que:

\footnotetext{
1.3. Agência de Publicidade ou Agência de Propaganda: é nos termos do art. $6^{\circ}$ do Dec. $n^{\circ} 57.690 / 66$, empresa criadora/produtora de conteúdos impressos e audiovisuais especializada nos métodos, na arte e na técnica publicitárias, através de profissionais a seu serviço que estuda, concebe, executa e distribui propaganda aos Veículos de Comunicação, por ordem e conta de Clientes Anunciantes com o objetivo de promover a venda de mercadorias, produtos, serviços e imagem, difundir ideias ou informar o público a respeito de organizações ou instituições a que servem. (2012, online)
}

Dyer acrescenta: "[ $\mathrm{t}]$ he advertising agent usually provides a market-research service for clients as well as designing and producing ads, and buying space in the media." (1996, p. 74)

Ferreira (1985, p. 50) considera agência de propaganda a "empresa de serviços que planeja, executa, distribui e controla a propaganda comercial dos seus clientes.

No mesmo sentido, Giacomini Filho (1991, p. 87) ensina que “o negócio publicitário pode ser esquematizado com os elementos agência-veículo-cliente-mercado, embora muitas empresas realizem propaganda sem a intermediação de agências [...]".

Pelo visto, a pessoa jurídica agência publicitária, resultado da reunião de pessoas, máquinas e ideias, atua no mercado de massa para produzir, naturalmente, publicidade, que busca informar o consumidor e persuadi-lo, via meios de comunicação, para adquirir produtos e serviços disponíveis no mercado, estes fornecidos pelo anunciante.

\subsection{Sobre publicidade e propaganda}

Beltrão e Quirino prescrevem que a publicidade consiste em mensagem cultural, objeto do estudo da comunicação de massa, e complementam:

O mercado da mensagem cultural é, sem dúvida, um dos mais amplos, procurados e rendosos da nossa civilização ocidental [...] É que a mensagem cultural se propõe a atender as necessidades básicas da cultura do receptor, relativas ao conhecimento e uso dos bens que a inteligência criadora, a ação construtiva do homem e a dinâmica da vida social lhe podem proporcionar. (1986, p. 103) 
Já que interessa à consecução do presente estudo, impõe-se então aqui fazer considerações conceituais, en vol d'oiseau, sobre tal prática.

A lei federal $n^{\circ} .4 .680$, de 18 de junho de 1965, que dispõe sobre o exercício da profissão de Publicitário e do Agenciador de Publicidade, define propaganda:

Art. $5^{\circ}$. Compreende-se por propaganda qualquer forma remunerada de difusão de ideias, mercadorias ou serviços, por parte de um anunciante identificado.

Vê-se, pela redação do aludido artigo, com mesma composição literal do art. $2^{\circ}$, do decreto $n^{\circ} .57 .690$, de $1^{\circ}$ de fevereiro de 1966 , que regulamenta a mencionada lei, que não fez o legislador qualquer distinção entre os termos publicidade e propaganda.

D'autre façon, prescreve o aludido Código de Ética dos Profissionais da Propaganda que propaganda "é a técnica de criar opinião pública favorável a um determinado produto, serviço, instituição ou ideia, visando a orientar o comportamento humano das massas num determinado sentido", não importando aqui a finalidade do benefício econômico almejado, considerando a publicidade remunerada, podendo ou não ser propaganda.

Sendo a forma de comunicação, ou melhor, de interação/persuasão entre o vendedor do serviço, ideia ou produto, com o público que poderá vir a consumi-los, Giacomini Filho (1991, p. 15) diz que: "entende-se por publicidade ou propaganda, a forma de comunicação identificada e persuasiva empreendida, de forma paga, através dos meios de comunicação de massa".

Já outros autores, com louvável objetividade, fazem distinção entre propaganda e publicidade. Para Nunes Júnior, a propaganda é "toda forma de comunicação, voltada ao público determinado ou indeterminado, que, empreendida por pessoa física ou jurídica, pública ou privada, tenha por finalidade a propagação de idéias relacionadas à filosofia, à política, à economia, à ciência, à religião, à arte ou à sociedade" (2003, p. 16), e a publicidade é "o ato comercial de índole coletiva, patrocinado por ente público ou privado, com ou sem personalidade, no âmago de uma atividade econômica, com a finalidade de promover, direta ou indiretamente, o consumo de produtos e serviços" (NUNES JÚNIOR, 2001, p. 22-23).

No mesmo sentido, entende Francisco Rico-Perez (apud Benjamim, 2007, p. 318-319):

A diferença essencial entre a publicidade e a propaganda baseia-se no fato de que a primeira faz-se com a intenção de alcançar lucro, enquanto que a segunda exclui quase sempre a ideia de benefício econômico.

Em suma, verifica-se certa imprecisão (e até confusão), nas normas apresentadas, entre os dois termos enfocados, talvez por problemas de tradução (no inglês, publicity, propaganda e advertising têm conotações diversas), talvez por se tratar de atividade negocial relativamente recente entre nós. Por conta da clareza, optamos pela distinção exposta acima por Nunes Júnior e Rico-Pérez.

\subsection{Sobre anunciante}

O mesmo Código de Ética dos Profissionais da Propaganda define anunciante como a entidade, firma, sociedade ou indivíduo que utiliza a propaganda, também podendo ser chamado de cliente. No mesmo sentido aponta o art. $8^{\circ}$, do dito decreto $\mathrm{n}^{\mathrm{o}} 57.690 / 66$, uma vez que "consideram-se Clientes ou Anunciantes a entidade ou indivíduo que utiliza a propaganda".

As referidas normas-padrão do CENP ratificam:

1.2 Anunciante ou Cliente: é, nos termos do art. $8^{\circ}$ do Dec. $n^{\circ} 57.690 / 66$, empresa, entidade ou indivíduo que utiliza a propaganda. 
Destarte, o anunciante, para popularizar e impulsionar a venda de seus produtos e serviços, buscará os serviços da agência publicitária, executados por publicitários. Estes, conforme os fins almejados dantes definidos pelo anunciante (conforme o briefing, do qual se tratará adiante), operarão no sentido de prescrever a mensagem e a mídia adequadas, dentre outras variáveis do marketing mix.

Explica Jacobina (1996, p.17-18) que "a relação entre a agência e o anunciante inicia muito antes da própria peça publicitária”, considerando, pois, o anúncio, elaborado pela agência, "uma das etapas da estratégia mercadológica" adotada pelo anunciante, podendo nem ser considerada a mais importante. Aponta, ainda, que a responsabilidade da agência em relação aos possíveis danos causados aos consumidores está inteiramente ligada à profundidade dessa relação.

As mencionadas normas-padrão do CENP, a partir do seu item 3, prescrevem limitações e parâmetros para a relação contratual a ser celebrada entre agência e anunciante, bem como entre aquela e o veículo de comunicação.

\subsection{Sobre veículo de comunicação}

O Código de Ética exemplifica, no seu ${ }^{\circ} 4$, como sendo jornais, revistas, estações de rádio, TV, exibidores de cartazes e outras entidades que, uma vez autorizados, divulgam a propaganda, no valor dos preços pré-fixados em suas tabelas.

Conforme redação do art. $4^{\circ}$ da lei $n^{\circ} 4.680 / 65$, é considerado qualquer meio de comunicação visual ou auditiva (ou audiovisual, vale completar) que tenha capacidade de transmissão de mensagens de propagandas ao público, devendo ser reconhecido pelas entidades e órgãos de classe, ou seja, as associações civis locais e regionais de propaganda, como também pelos sindicatos de publicitários.

Pelo CENP, temos que:

1.4 Veículo de Comunicação ou, simplesmente, Veículo: é, nos termos do art. $10^{\circ}$ do Dec. $\mathrm{n}^{\circ} 57.690 / 66$, qualquer meio de divulgação visual, auditiva ou audiovisual

Feitas as considerações acima, para o publicitário e empresário Luiz Santos (2012, comunicação pessoal), da LS Estratégia, o termo agência está, entretanto, ultrapassado, devendo ser substituído o quanto antes, para que o negócio sobreviva, sendo mais adequado defini-la como "empresa de serviços de marketing", aquela que "responde pelas reflexões e os processos de solução de comunicação e de relacionamento, de uma empresa com os seus diversos públicos".

Pondera, ainda, que as agências publicitárias, como hoje postas, estão sendo preteridas pelos modos com que o mercado vem se estruturando, pois as relações negociais, mais e mais, efetivam-se diretamente. Portanto, se as agências insistirem em se colocar como intermediárias, terão necessidade de reaprenderem a estimar os honorários a serem pagos pelo anunciante, que são irrisórios, já que a verdadeira remuneração ocorre pelos veículos de divulgação.

Tal entendimento é ratificado por Walter Longo:

[...] ao mesmo tempo em que a Agência de Propaganda deve ter a coragem para rever seus serviços e ampliar suas responsabilidades, o anunciante precisa entender que a mais serviços correspondem mais custos, deixando de esperar gratuidades nas atividades adicionais (1995, p. 303-347) 


\section{Aspectos do CONTRATO DE PRESTAÇÃo DE SERVIÇOS PUBLICITÁRIOS}

Entende Caio Mário da Silva Pereira $(2012$, p. 7) que contrato é "um acordo de vontades, na conformidade da lei, e com finalidade de adquirir, resguardar, transferir, conservar, modificar ou extinguir direitos".

Diniz (2000, p. 23) acrescenta: “a essência do negócio jurídico é a autorregulamentação dos interesses particulares, reconhecida pela ordem pública, que lhe dá força criativa", e, complementa, que "o contrato é o acordo de duas ou mais vontades, na conformidade da ordem jurídica, destinado a estabelecer uma regulamentação de interesses entre as partes [...]”.

Para Gonçalves (2010, p. 21), o contrato é "a mais comum e a mais importante fonte de obrigação, devido às suas múltiplas formas e inúmeras repercussões no mundo jurídico”, uma vez que, para o Código Civil de 2002 (CC), os contratos são tidos como um dos fatos humanos geradores de obrigações.

Leciona, ainda, que "a economia de massa exige contratos impessoais e padronizados (contratos-tipo ou de massa), que não mais se coadunam com o princípio da autonomia da vontade”, este, como um dos mais importantes princípios que regem o direito contratual, tendo o seu alicerce na ampla liberdade de pactuar, que estabelece que os contratantes são livres para "contratar se quiserem, com quem quiserem e sobre o que quiserem" (GONÇALVES, 2010, p. 41).

Ensina Gomes (1999, p. 10) que o contrato, que é negócio jurídico bilateral ou plurilateral, submete as partes que o celebraram "à observância de conduta idônea à satisfação dos interesses que regularam", ou seja, as disposições contratuais constituem verdadeira lei entre as partes (pacta sunt servanda), vinculando a conduta de cada uma. Explica, ainda, que, na prática:

[...] emprega-se a palavra contrato em acepções distintas, ora para designar o negócio jurídico bilateral gerador de obrigações, ora o instrumento em que se formaliza, seja a escritura pública, o escrito particular de estilo, simples missiva, ou um recibo. (1999, p. 9)

Para tanto é necessário que o contrato observe alguns elementos indispensáveis para a sua validade, como Clóvis Beviláqua ministra:

Para que os contractos tenham eficaccia juridica, será necessario que se perfaçam, segundo certas normas e condições que dizem respeito, umas aos contractos propriamente e outras aos contrahentes, pelo que se podem chamar, as primeiras, condições e normas objectivas e as segundas, subjectivas. (1977, p. 159)

Feita esta aligeirada apresentação, passa-se ao exame da espécie contratual que rege a relação anunciante-agência-veículo, qual seja, a de prestação de serviços publicitários. Distinguir-se-á, ainda, essa espécie da que trata do contrato de agência, uma vez que pode haver confusão quanto à nomenclatura por este perfilhada quando feita análise meramente perfunctória da leitura das espécies contratuais.

O contrato de prestação de serviços era previsto pelo Código Civil de 1916 com o nome de locação de serviços (locatio conductio operarum), o que, sob o título de locação, eram estabelecidos, além desse, mais dois: a locação de coisas (locatio conductio rerum) e a empreitada (locatio condutio operis), unidade conceitual herdada dos romanos e mantida pelo Código. Nas palavras de Wald:

[...] no Direito Romano, havia três figuras com nomes começando pela palavra Locatio: locatio rerum, locatio operis e locatio operarum. A primeira é a locação de coisas; a segunda (locação de obra) é o que se chama de empreitada; a terceira, o que se chamou, no Código Civil de 1916, de locação de serviços e hoje se considera mais adequado chamar de prestação de serviços. (2000, p. 426) 
O Código Civil de 2002, no entanto, disciplinou de forma diversa, separando a prestação de serviços das demais espécies de locações, esta apenas sendo utilizada para qualificar aqueles contratos que se destinassem a permitir a alguém, durante um tempo, o uso e gozo de uma coisa infungível com a devida retribuição. Tal separação, segundo Pereira, decorreu de uma nova perspectiva adotada, em que "o direito moderno não mais considera o trabalho humano uma coisa suscetível de dar-se em locação” (2012, p. 345).

Nesse sentido, o contrato dantes chamado de locação de serviços, dividiu-se em contrato de trabalho, hoje sujeito à Consolidação das Leis Trabalhistas (CLT), decreto $n^{\circ}$. 5.452/43, e em contrato de prestação de serviços, regido pelo atual CC em seus arts. 593 a 609. Para Gomes (1999, p. 290), este último não se adequa "ao conceito legal do contrato de trabalho, seja pela inexistência de subordinação, pela falta de continuidade [...]”, como prevê o art. 593 do CC, que dispõe que a prestação de serviços, quando não estiver sujeita às leis trabalhistas ou à lei especial, será por ele regida, ou seja, aquele executado sem habitualidade, com autonomia técnica e sem subordinação.

Esclarece, ainda, Gonçalves que, dada a universalidade de prestação de serviço, será ele ora regulado pela legislação trabalhista, como o que acontece com o serviço doméstico e o rural; ora pelo direito público ou por legislação especial, como no caso dos serviços prestados por grandes empresas ao público em geral, instituições financeiras, bem como as relações de consumo que são reguladas pelo Código de Defesa do Consumidor (CDC, lei n 8.078/90):

\footnotetext{
O próprio Código Civil passou a disciplinar, como figuras típicas e nominadas, os contratos de transporte (arts. 730 a 756), de corretagem (arts. 722 a 729), de agência e distribuição (arts. 710 a 721), de comissão (arts. 693 a 709), havendo ainda inúmeros contratos atípicos que têm por objeto a prestação de serviços, como os de hotelaria e de estacionamento de veículos. (GONÇALVES, 2010, p. 359)
}

Dito isso, o contrato de prestação de serviços é então definido pelo Código Civil de 2002, em seu art. 594, como "toda a espécie de serviço ou trabalho lícito, material ou imaterial, pode ser contratada mediante retribuição”, ou seja, qualquer serviço prestado, uma vez que lícito, poderá ser objeto contratual dessa relação obrigacional, não sendo necessária a distinção entre trabalho braçal ou intelectual (GONÇALVES, 2010, p.360).

Para Venosa (2010, p. 209), trata-se de "contrato signalagmático pelo qual uma das partes, denominada prestador, obriga-se a prestar serviços a outra, denominada dono do serviço, mediante remuneração", ou seja, é o contrato bilateral, uma vez que cria direitos e obrigações para ambas as partes, sendo, assim, oneroso, que se aperfeiçoa pelo simples acordo de vontades, daí ser consensual, e, por fim, comutativo, pois impõe vantagens e obrigações recíprocas, pressupondose equivalentes, de conhecimento das partes. Assim, no contrato firmado entre o anunciante e a agência, esta seria a prestadora e aquele, o tomador do serviço.

Já para Wald (2000, p. 426), a definição de contrato de prestação de serviços implica naquele em que uma pessoa estipula uma atividade lícita, em caráter eventual e autônomo, sem subordinação do prestador e mediante remuneração", entendendo, nesse sentido, que:

[...] se a pessoa contrata os serviços de um advogado, ou consulta um médico particular, ou chama um trabalhador autônomo para um conserto (um bombeiro encanador, um pintor autônomo), há contrato de prestação de serviços. (2000, p. 426)

Assim, haverá também contrato de prestação de serviços no caso de um empresário que deseja promover suas vendas a partir da divulgação do seu produto, o que, para atrair o público, buscará a assessoria de uma agência publicitária que executará e distribuirá propaganda aos veículos de divulgação. 
Explica Gomes, quanto à ausência de subordinação, que:

A parte que presta o serviço estipulado não o executa sob a direção de quem se obriga a remunerá-lo e utiliza os métodos e processos que julga convenientes traçando, ela própria, a orientação técnica a seguir, e assim exercendo sua atividade profissional com liberdade. (1999, p. 292-293)

Pereira (2012, p. 348) conceitua o contrato civil de prestação de serviços como "aquele em que uma das partes se obriga para com a outra a fornecer-lhe a prestação de sua atividade, mediante remuneração", o que, consequentemente, para ele, o referido contrato apresenta como elementos essenciais o objeto da obrigação, a remuneração e o consentimento.

Nesse sentido, quanto ao objeto, é ele uma obrigação de fazer, ou seja, a prestação da atividade, que pode ser tanto intelectual como material; terá o trabalhador, ou melhor, o prestador do serviço, direito a uma remuneração ou retribuição, contraprestação, convencionada livremente, normalmente importando em prestação pecuniária; o consentimento , que pressupõe o acordo de vontades, manifestado por escrito ou oralmente, ou até mesmo de modo implícito.

Compreendido o contrato de prestação de serviços e considerando que regulará a relação anunciante-agência-veículo, necessário se faz distingui-lo do contrato de agência, conforme Wald:

É preciso não confundir a prestação de serviços com outros contratos em que também há prestação, mas tipificados com outro nome ou com características especiais. Assim, o mandato, a gestão de negócios, a representação comercial ou o contrato de transporte, certos contratos bancários e outros de transmissão de tecnologia [...]. (2000, p. 428-429)

Assim, reza o art. 710 do CC que, no contrato de agência, uma pessoa assume, em caráter não eventual e sem vínculos de dependência, por meio de retribuição, a obrigação de promover, à conta de outra, a realização de certos negócios, em zona determinada, caracterizandose a distribuição quando o agente tiver à sua disposição a coisa a ser negociada.

Dessa redação é possível entender que o contrato de agência implicará quando o agente não estiver com a coisa a ser negociada, o que, do contrário, tratar-se-á de contrato de distribuição.

Entende Gomes (1999, p. 365) que o contrato de agência, também chamado de agenciamento ou representação contratual, se estabelece quando uma das partes contratantes "obriga-se, contra retribuição, a promover habitualmente a realização por conta da outra, em determinada zona, de operações mercantis, agenciando pedidos para esta”, assim, constituindo sua composição: a) a obrigação do agente de promover a conclusão de contratos por conta do proponente; b) a habitualidade do serviço, c) delimitação da zona onde deve ser prestado; d) direito do agente à retribuição do serviço que presta; e e) exclusividade e independência de ação. Para o autor, o traço marcante é a autonomia na prestação de serviço.

Destaca, ainda, Bulgarelli (2000, p. 511-512) que o contrato de agência "é hoje verdadeiro contrato típico, devidamente regulado pela lei $\mathrm{n}^{\circ}$. 4.886, de 9 de dezembro de 1965, que o conceitua:

Art. $1^{\circ}$. Exerce a representação comercial autônoma a pessoa jurídica ou a pessoa física, sem relação de emprego, que desempenha, em caráter não eventual por conta de uma ou mais pessoas, a mediação para a realização de negócios mercantis, agenciando propostas ou pedidos, para, transmiti-los aos representados, praticando ou não atos relacionados com a execução dos negócios. 
Compreende Bittar (1994, p. 81) que “a representação é, pois, atividade de gerenciamento de negócios, que se concretiza, através de profissional, ou de empresa comercial especializada, sob registro próprio", configurando, por conseguinte, atividade mercantil que implica na conquista de novos mercados pelos produtores ou fabricantes, sem que estes tenham que instituir filiais, sucursais ou agências próprias.

Adverte, ainda, Gomes (1999, p. 367), quanto ao surgimento de figuras características e atípicas de agentes, como o agente depositário, agente livreiro, o agente propagandista (este em nada tem relação com o presente estudo, pois trata-se de figura correlata à indústria farmacêutica que distribui amostras de medicamentos), agente cinematográfico, agente esportista, dentre outros que surgiram com a necessidade econômica de representação em determinados locais, daí surgindo o contrato de agência, antes inominado.

Enfim, feita a diferenciação entre as espécies de contrato passíveis de causar confusão devido à nomenclatura atribuída pelo código que as regulamenta, ainda é cabível mencionar a lei federal $\mathrm{n}^{\mathrm{o}}$. 12.232/2010, que trata da contratação pela administração pública de serviços de publicidade prestados por intermédio de agências de propaganda.

\section{DA RESPONSABILIDADE E SOLIDARIEDADE DA AGÊNCIA PUBLICITÁRIA}

Importa agora enfocar a questão da responsabilidade da agência publicitária quando a peça por ela produzida (encomendada e aprovada pelo anunciante e veiculada pela mídia, enfatize-se) faltar com a verdade, causar medo, provocar preconceito, deturpar informações, dentre outras situações ilícitas.

Recorrendo aos conceitos supra, questiona-se, no caso de anúncio - tido como propaganda ou publicidade - mostrar-se incompatível com os interesses sociais, caracterizando-se como enganoso ou abusivo: a quem deverá ser atribuída a responsabilidade pelos consequentes danos dele advindos?

Pode caber aos criadores da publicidade, aos publicitários, que, regra geral, têm formação de nível superior e (pelo menos) devem conhecer (como prescreve o CDC) nuanças da legislação sobre sua atividade profissional. Pode recair sobre os veículos, que tornam pública, para milhões, mensagem publicitária sem cuidado e compromisso necessários e adequados com o seu conteúdo. Ou pode ainda caber ao anunciante, que encomendou o anúncio e pagou pela sua veiculação, dela se beneficiando.

Santos (2006, p. 206) ressalta que, antes do CDC, não havia regulamentação adequada e suficiente da atividade publicitária voltada para os interesses dos consumidores. Existiam (e existem) tão somente a dita lei $\mathrm{n}^{\circ} 4.680 / 65$ e seu decreto $\mathrm{n}^{\circ} 57.690 / 66$, regulamentador, que, de maneira assistemática e precária, como já demonstrado, buscavam disciplinar a atividade. Em 1978, a aprovação do Código Brasileiro de Ética e Autorregulamentação Publicitária (CBAP) trouxe certo alento, mas trata-se de regramento exclusivamente privado da atividade publicitária, realizada pelos próprios profissionais do setor, daí concluindo-se que:

Fato é que a publicidade, por sua alta relevância, não mais pode ser ignorada pelo Direito, como o foi até tempos recentes, pois os efeitos danosos de sua má utilização são deveras insalubres não só aos consumidores e consumidores em potencial, mas a todo o mercado. (SANTOS, 2000, p. 199)

Destaque-se que o Conselho Nacional de Autorregulamentação Publicitária (Conar), associação civil integrada pelos atores do mercado publicitário (agência, anunciante e veículo), com seu código, almeja impor conduta ética ao setor, atuando como "primeiro filtro" da atividade 
publicitária. A fiscalização pelo Conar certamente leva a uma redução de demandas judiciais, daí sua importância no contexto jurídico publicitário; porém, não pode ser visto como o único controlador dos excessos da publicidade, pois revela-se ineficaz (SANTOS, 2000, p. 209).

No plano legiferado, em termos mais recentes, cite-se o relevante papel exercido pelo CDC, ao dispor sobre publicidade enganosa e abusiva:

\footnotetext{
Art. 37. É proibida toda publicidade enganosa ou abusiva.

$\S 1^{\circ}$ - É enganosa qualquer modalidade de informação ou comunicação de caráter publicitário, inteira ou parcialmente falsa, ou, por qualquer outro modo, mesmo por omissão, capaz de induzir em erro o consumidor a respeito da natureza, características, qualidade, quantidade, propriedades, origem, preço e quaisquer outros dados sobre produtos e serviços.

$\S 2^{\circ}$ - É abusiva, dentre outras, a publicidade discriminatória de qualquer natureza, a que incite à violência, explore o medo ou a superstição, aproveite-se da deficiência de julgamento e experiência da criança, desrespeite valores ambientais, ou que seja capaz de induzir o consumidor a se comportar de forma prejudicial ou perigosa à sua saúde ou segurança.

$\S 3^{\circ}$ - Para os efeitos deste código, a publicidade é enganosa por omissão quando deixar de informar sobre dado essencial do produto ou serviço.
}

Jacobina (1996, p. 18-19) analisa a responsabilidade da publicidade patológica (enganosa ou abusiva) da seguinte forma: entende que a elaboração da peça publicitária inicia-se com pesquisa e planejamento, que permitirão definir as estratégias mercadológicas utilizadas na venda do produto ou serviço, uma vez que estarão disponíveis no briefing (documento elaborado pela agência, a partir de informações dadas pelo anunciante, que serve de base para criação do anúncio publicitário, que aborda as características do produto ou serviço, o público-alvo e os objetivos da campanha). Segundo o autor, é o briefing documento juridicamente considerável, pois permite a avaliação da responsabilidade da agência quanto ao conteúdo patológico da publicidade, muita vez usado pela agência para eximir-se de responder pelo conteúdo causador de prejuízos, justificando que ela mesma fora ludibriada e que recebera dados falsos do próprio anunciante.

Nesse sentido, ensina Benjamin (2007, p. 320-323) que “a criação publicitária tem repercussão jurídica, na medida em que vai interessar ao Direito saber por quem e como foi elaborada a mensagem (enganosa ou abusiva, por exemplo)".

Acresça-se que "na publicidade, pelo menos no sistema brasileiro, não é a vontade real do anunciante a fonte da obrigação contratual, mas o anúncio em si, ou seja, a declaração, tal qual explicitada", segundo Benjamin (2007, p. 298).

Para Cavalieri Filho (2010, p. 2), responsabilidade civil "designa o dever que alguém tem de reparar o prejuízo decorrente da violação de um outro dever jurídico", definindose como "um dever jurídico sucessivo que surge para recompor o dano decorrente da violação de um dever jurídico originário".

O referido código do Conar, no seu art. $3^{\circ}$, dispõe que "todo anúncio deve ter presente a responsabilidade do Anunciante, da Agência de Publicidade e do Veículo de Divulgação"; em outras palavras, todos aqueles que concorrerem para o anúncio são responsáveis pelos danos causados pela sua veiculação.

Furthermore, em seu art. 45, prevê que a responsabilidade pela observância das normas de conduta estabelecidas pelo referido código cabe solidariamente aos três players, salvo algumas reservas quanto ao veículo. 
Sobre solidariedade, Pereira ensina:

Para que se possa vislumbrar a solidariedade é de mister que haja a concorrência
de mais de um credor, ou de mais de um devedor, ou de vários credores e vários
devedores simultaneamente [...] pluralidade subjetiva e unida objetiva: é da essência
da solidariedade que numa obrigação em que concorram vários sujeitos ativos ou
vários sujeitos passivos haja unidade de prestação, isto é, cada um dos credores tem o
poder de receber a dívida inteira, e cada um dos devedores tem a obrigação de solvê-la
integralmente. (2008, p. 91)

Preventivamente, recomenda o mesmo art. 45 do código do Conar que o veículo estabeleça um sistema de controle para receber os anúncios, podendo até mesmo chegar a recusar, quando entender que o seu conteúdo fere, flagrantemente, princípios do código, independentemente de decisão prévia do conselho.

Determina ainda que a responsabilidade do veículo se equipara à do anunciante sempre que a veiculação do anúncio contrariar os termos de recomendação que lhe tenha sido comunicada formalmente pelo Conar.

Entende Benjamin (2007, p. 367) que o anunciante tem responsabilidade civil objetiva pela publicidade enganosa ou abusiva, o que também terá pelo cumprimento do princípio da vinculação da mensagem publicitária (arts. 30 e 35, do CDC). No entanto, não estão excluídas as responsabilidades da agência e do próprio veículo, que responderão solidariamente, conforme regra do $\mathrm{CDC}$, sendo essa solidariedade limitada, uma vez que, segundo o doutrinador, só serão considerados corresponsáveis quando agirem dolosa ou culposamente.

Benjamin informa que há corrente contrária ao seu entendimento, liderada por Nelson Nery Júnior, José Paulo Scartezzini Guimarães, José Antônio de Almeida e Rizzato Nunes, que atribuem a responsabilidade civil objetiva também à agência e ao veículo, com base nas normas do CDC.

Rizzato Nunes (2011, p. 556-557), conforme acima mencionado, representando a corrente oposta à já comentada, entende que a responsabilidade do anunciante, da agência e do veículo é solidária, de acordo com previsão do art. $7^{\circ}$ do CDC, Parágrafo único. Ademais, observa que o "fornecedor-anunciante" será sempre responsabilizado pelos danos que o seu anúncio causar e que "a agência, como produtora do anúncio, responde solidariamente com o anunciante, independentemente do tipo de contrato que com ele tenha estabelecido", ou seja, no contrato de prestação de serviços entre anunciante e agência, a cláusula que estabeleça a responsabilidade exclusiva daquele, após a sua aprovação, só será válida entre eles, sendo garantido à pessoa lesada pela publicidade enganosa acionar qualquer um deles (solidários que são).

Entretanto, quanto à responsabilidade da agência, aponta ainda Rizzato Nunes (2011, p. 557) que esta poderá ser "desresponsabilizada", nos casos em que a agência participe apenas como "mera produtora de uma informação encomendada", em que a enganosidade não está objetivamente disposta no anúncio, mas dependente da atitude do anunciante, como, por exemplo, quando o "fornecedor-anunciante encomenda para a agência a elaboração de anúncio para inserção em jornais e revistas, oferecendo $50 \%$ de desconto em seus produtos", o que, depois de feita a publicidade pela agência, os consumidores descobrem que o desconto é apenas de $20 \%$.

\section{Posicionamento dos tribunais}

Feitas as considerações cabíveis acerca da responsabilidade da agência publicitária, que poderá responder solidária e objetivamente com o anunciante quando da veiculação de 
anúncios publicitários causadores de prejuízos, passa-se à análise do posicionamento recente dos tribunais sobre a matéria.

Em pesquisa realizada nos sítios eletrônicos do Superior Tribunal de Justiça e de alguns Tribunais de Justiça, detectaram-se, nos últimos três anos, as seguintes decisões dignas de registro:

Na apelação cível n. 2008.033937-6, de Blumenau (SC), entendeu o Desembargador Relator Luiz Carlos Freyesleben que nem a concessionária de veículos, nem sua agência publicitária, nem o sítio eletrônico do fornecedor poderiam ser responsabilizados por propaganda alegavelmente enganosa, pois o anúncio sobre compra de veículo em parcelas mensais não levava o consumidor a erro.

Na apelação cível n. 2010.040486-9, de Joaçaba (SC), o Desembargador Relator Fernando Carioni, em seu voto, manifestou-se pela ilegitimidade passiva de duas redes de televisão, que veicularam anúncio alegavelmente enganoso, destacando:

\footnotetext{
As empresas de comunicação não respondem por publicidade de propostas abusivas ou enganosas. Tal responsabilidade toca aos fornecedores-anunciantes, que a patrocinaram (CDC, Arts. $3^{\circ}$ e 38 ). O CDC, quando trata de publicidade, impõe deveres ao anunciante - não às empresas de comunicação (Art. $3^{\circ}$, CDC)" (STJ, REsp n. 604.172/SP, rel. Min. Humberto Gomes de Barros, j. em 27-3-2007).
}

Já o fornecedor-anunciante foi condenado pelo tal anúncio enganoso, mormente por força dos arts. $3^{\circ}$ e 38 do CDC; porém vale destacar que o relator referiu-se também ao art. $6^{\circ}$ da mesma lei, destacando que lá não se incluem direitos básicos do consumidor perante veículo ou agência, mas somente contra o fornecedor, a quem cabe provar com dados fáticos, técnicos e científicos a veracidade do anúncio.

Permitimo-nos, entretanto, discordar, levando em conta o inc. IV do art. $6^{\circ}$ já aludido, que estabelece como direito básico do consumidor:

IV - a proteção contra a publicidade enganosa e abusiva, métodos comerciais
coercitivos ou desleais, bem como contra práticas e cláusulas abusivas ou impostas
no fornecimento de produtos e serviços;

Ora, certo é que a segunda parte aplica-se ao fornecedor-anunciante, mas a primeira do trecho supra pode ser aplicável, indubitavelmente, a quem elabora e/ou veicula "publicidade enganosa e abusiva": agência e veículo, respectivamente.

Para embasar seu entendimento acerca da ilegitimidade passiva ad causam do veículo, acostou ao seu voto, no mesmo sentido: do TJRJ, o AI n. 2007.002.24269, de Cabo Frio, rela. desa. Letícia de Faria Sardas, j. em 12-9-2007 e, do TJMG, a Ap. Cív. n. 2.0000.00.5111146/000(1), de Belo Horizonte, rel. des. Afrânio Vilela, j. em 3-8-2005.

$\mathrm{Na}$ apelação cível $n^{0} 70048989545$, movida pela Natuphitus Indústria e Comércio de Cosméticos Ltda. e outros, contra o Ministério Público, no Tribunal de Justiça do Estado do Rio Grande do Sul, fabricante e comerciante foram responsabilizados, juntamente com os sócios daquele (por conta da disregard doctrine), para indenizar consumidores de pomada anunciada como medicamento, mas que na verdade tinha apenas natureza cosmética. Não houve referência específica à agência publicitária, não obstante a caracterização do anúncio enganoso divulgando o produto quase "milagroso".

No Superior Tribunal de Justiça (STJ), pelo REsp no 997.993 - MG (2007/02476356), o Ministro Relator Luis Felipe Salomão votou pela responsabilidade solidária da TV Juiz de Fora Ltda., proprietária de sítio eletrônico que hospedava outro sítio eletrônico, da empresa Mídia 
Um Publicidade Propaganda e Marketing Ltda., pelo descaso na publicação de anúncio erótico falso, apenando todos os que participaram da cadeia de consumo. Por entender que se cuidava de "relação de consumo por equiparação, decorrente de evento relativo à utilização de provedores de conteúdo na rede mundial de computadores, organizados para fornecerem serviços em cadeia para os usuários", aplicou a principiologia do CDC, apurando a responsabilidade de cada um deles, objetiva ou decorrente de culpa.

Já no notório REsp nº 69.134 - SP (1995/0032942-5), o Ministro Relator Barros Monteiro, diante da violação de direito moral de fotógrafo, na falta de identificação deste como autor de fotografia utilizada em material publicitário da empresa anunciante Sé Comércio e Indústria $\mathrm{S} / \mathrm{A}$, entendeu que cabe também à agência publicitária WBrasil solidariamente responder pelo dano moral causado ao referido profissional. Não há falar, na espécie, em ilegitimidade passiva ad causam da agência, que não agiu como simples mandatária da anunciante Sé, pois à primeira cabe "observar e cumprir os requisitos legais exigidos para viabilizar e executar a encomenda".

\section{CONSIDERAÇÕES FINAIS}

Conforme demonstrado, o tema ainda não se esgotou, pois cada situação contratual deve ser analisada com a devida cautela, uma vez que os dispositivos legais revelam-se ainda pouco esclarecedores.

A nosso ver, em regra, cabe, sim, à agência publicitária responder solidariamente pela concepção e produção de anúncio enganoso e/ou abusivo, divulgado por veículo de comunicação que ela indicou e/ou contratou, por ordem e conta do anunciante.

Em termos gerais, repise-se, pouco importa se o anunciante aprovou previamente a peça publicitária patológica concebida pela agência, pois, no exercício do seu ofício, que demanda conhecimento técnico sofisticado e, muita vez, pouco acessível ao anunciante, ao publicitário compete agir com o necessário zelo para evitar dano à imagem do seu cliente e ao público consumidor. Até porque a agência beneficia-se financeiramente da divulgação da peça por ela produzida para seu cliente.

\section{REFERÊNCIAS}

BELTRÃO, Luiz e QUIRINO, Newton de Oliveira. Subsídios para uma teoria da comunicação de massa. 2 ed. São Paulo: Summus, 1986.

BENJAMIN, Antônio Herman et al. Comentários ao Código de Defesa do Consumidor: comentado pelos autores do anteprojeto. 9 ed. Rio de Janeiro: Forense Universitária, 2007.

BITTAR, Carlos Alberto. Contratos comerciais. 2 ed. Rio de Janeiro: Forense Universitária, 1994.

BRASIL. Código de Ética dos Profissionais da Propaganda. Disponível: <http://www.janela. com.br/textos/CodigoDeEtica.html>. Acesso em: 9.nov.2012.

BRASIL. Código Brasileiro de Auto-Regulamentação Publicitária. Disponível em: <http:// www.janela.com.br/textos/Auto-Regulamentacao.html>. Acesso em: 9.nov.2012.

BRASIL. Decreto 57.690, de 1 de fevereiro de 1966. Aprova o Regulamento para a execução da Lei n $n^{\text {0 }}$.680, de 18 de junho de 1965. Disponível em: <http://www.planalto.gov.br/ccivil_03/ decreto/D57690.htm>. Acesso em: 9.nov.2012. 
Lei $n^{0}$ 4.680, de 18 de junho de 1965. Dispõe sobre o exercício da profissão de Publicitário e de Agenciador de Propaganda e dá outras providências. Brasília, DF: Poder Executivo, 1965. Disponível em: <http://www.planalto.gov.br/ccivil_03/leis/L4680.htm>. Acesso em: 3.nov.2012.

Lei no 8.078, de 11 de setembro de 1990. Dispõe sobre a proteção do consumidor e dá outras providências. Brasília, DF: Poder Executivo, 1965. Disponível em: <http://www.planalto. gov.br/ccivil_03/leis/L8078.htm>. Acesso em: 9.nov.2012.

BULGARELLI, Waldirio. Contratos mercantis. 12 ed. São Paulo: Atlas, 2000.

CAVALIERI FILHO, Sergio. Programa de responsabilidade civil. 9 ed. São Paulo: Atlas, 2010. CONSELHO EXECUTIVO DAS NORMAS-PADRÃO. Disponível em: < http://www.janela. com.br/textos/Cenp.html>. Acesso em: 9.nov.2012.

DYER, Gillian. Advertising as communication. London: Routledge, 1996.

BARSA. Dicionário Brasileiro da língua portuguesa. 14 ed. São Paulo: Melhoramentos, 1994.

FERREIRA, Aurélio Buarque de Holanda. Novo dicionário da língua portuguesa. 1 ed. Rio de Janeiro: Nova Fronteira, 1985.

GIACOMINI FILHO, Gino. Consumidor versus propaganda. São Paulo: Summus, 1991.

GOMES, Orlando. Contratos. 18 ed. Rio de Janeiro: Forense, 1999.

GONÇALVES, Carlos Roberto. Direito civil brasileiro: contratos e atos unilaterais. 7 ed. v. 3. São Paulo: Saraiva, 2010.

JACOBINA, Paulo Vasconcelos. A publicidade no direito do consumidor. Rio de Janeiro: Forense, 1996.

LONGO, Walter. Atendimento. In: RIBEIRO, Júlio et al. Tudo que você queria saber sobre propaganda e ninguém teve paciência para explicar. São Paulo: Atlas, 1995, p. 303-347.

JÚNIOR, Vidal Serrano Nunes e SERRANO, Yolanda Alves Pinto. Código de Defesa do Consumidor interpretado. São Paulo: Saraiva, 2003.

. Publicidade comercial: proteção e limites na Constituição de 1988. São Paulo: Juarez de Oliveira, 2001.

PEREIRA, Caio Mário da Silva. Instituições de direito civil: contratos. 16 ed. Rio de Janeiro: Forense, 2012.

NUNES, Luis Antonio Rizzatto. Curso de direito do consumidor. 6 ed. rev. e atual. São Paulo: Saraiva, 2011.

SANTOS, Fernando Gherardini. Direito do Marketing: uma abordagem jurídica do marketing empresarial. São Paulo: Revista dos Tribunais, 2000.

SANTOS, Luiz. Comunicação pessoal. 2012

SUPERIOR TRIBUNAL DE JUSTIÇA. Recurso especial nº 997993, 4ª Turma do Superior Tribunal de Justiça, Brasília, DF, 21 jun. 2012. Disponível em: < https://ww2.stj.jus.br revistaeletronica/ita. asp? registro $=200702476356 \& d t$ publicacao=06/08/2012>. Acesso em: 11.nov.2012. 
. Recurso especial no 69134, 4a Turma do Superior Tribunal de Justiça, Brasília, DF, 19 set. 2000. Disponível em: $<$ https://ww2.stj.jus.br/revistaeletronica/ita.asp?registro=199500329425\&dt publicacao=30/10/2000>. Acesso em: 11.nov.2012.

TRIBUNAL DE JUSTIÇA DO ESTADO DO RIO GRANDE DO SUL. Apelação Cível nº 70048989545, 12 a Câmara Cível do Tribunal de Justiça do Estado de Rio Grande do Sul, 12 jul. 2012. Disponível em: <http://www.jusbrasil.com.br/jurisprudencia/21945655/apelacaocivel-ac-70048989545-rs-tjrs/inteiro-teor>. Acesso em: 11.nov.2012.

TRIBUNAL DE JUSTIÇA DO ESTADO DE SANTA CATARINA. Apelação Cível nº 404869 (2010.040486-9), 3ª Câmara Cível do Tribunal de Justiça de Santa Catarina, 30.ago.2010. Disponível em: <http://www.jusbrasil.com.br/jurisprudencia/18366379/apelacao-civel-ac404869-sc-2010040486-9-tjsc>. Acesso em: 11.nov.2012.

. Apelação Cível no 339376 (2008.033937-6), 2 Câmara Cível do Tribunal de Justiça do Estado de Santa Catarina, 21 out. 2010. Disponível em: <http://www.jusbrasil.com.br/ jurisprudencia/18796954/apelacao-civel-ac-339376-sc-2008033937-6-tjsc >. Acesso em: 11.nov.2012.

VENOSA, Sílvio de Salvo. Direito Civil: contratos em espécie. 10 ed. v. 3. São Paulo: Atlas, 2010.

WALD, Arnoldo. Obrigações e contratos. 14 ed. rev. atual. e ampl. São Paulo: Revista dos Tribunais, 2000.

\section{CIVIL RESPONSIBILITY OF THE ADVERTISING AGENCY}

Abstract: This article discusses the contractual effects produced by the business relations leading to advertisement, which involves both the advertising agency and its client, and the agency and the means of communication. Legal theory, the statutes and jurisprudence are analyzed here to understand the degree of civil responsibility attributed to the advertising agency when conceiving/producing a socalled pathological advert.

Keywords: Advertising agency. Civil responsibility. Tort. Damages. 